\title{
Sequential MPC Strategy for High Performance Induction Motor Drives: a detailed analysis
}

\author{
Valerio Vodola \\ Dept. of Energy \\ Politecnico di Torino \\ Turin, Italy \\ valerio.vodola@gmail.com
}

\author{
Cristian Garcia \\ Dept. of Electrical Engineering \\ Universidad de Talca \\ Talca, Chile \\ cgarciap7@gmail.com \\ Jose Rodriguez \\ Dept. of Engineering Science \\ Universidad Andres Bello \\ Santiago, Chile \\ jose.rodriguez@unab.cl
}

\author{
Shafiq Odhano \\ Dept. of Electrical and Electronic \\ Engineering \\ University of Nottingham \\ Nottingham, UK \\ shafiq.odhano@nottingham.ac.uk
}

$$
\begin{gathered}
\text { Silvio Vaschetto } \\
\text { Dept. of Energy } \\
\text { Politecnico di Torino } \\
\text { Turin, Italy } \\
\text { silvio.vaschetto@polito.it } \\
\\
\text { Radu Bojoi } \\
\text { Dept. of Energy } \\
\text { Politecnico di Torino } \\
\text { Turin, Italy } \\
\text { radu.bojoi@polito.it }
\end{gathered}
$$

\author{
Margarita Norambuena \\ Dept. of Electrical Engineering \\ Universidad Tecnica Federico Santa \\ Maria \\ Valparaiso, Chile \\ margarita.norambuena@gmail.com \\ Pericle Zanchetta \\ Dept. of Electrical and Electronic \\ Engineering \\ University of Nottingham \\ Nottingham, UK \\ pericle.zanchetta@nottingham.ac.uk
}

\begin{abstract}
The paper deals with a newly developed sequential model predictive control strategy for the highperformance control of electric drives. The sequential nature of cost function evaluation allows to eliminate weighting factors whose tuning is not straightforward. In the first cost function evaluation, torque (or flux) error is minimized and, the second evaluation minimizes the flux (or torque) error. The first optimization generates two optimal voltage vectors that give minimum error for the controlled variable and the second optimization tests only the selected two vectors to find the global optimal. In this paper, a detailed analysis of the sequential MPC is carried out with a focus on the inversion of sequence of optimization with respect to the original algorithm. The paper also analyses the effect of selecting more than two vectors from the first evaluation and explains to the reader why some numbers of selected vectors produce flux and torque distortions while others do not control flux and torque at all
\end{abstract}

Keywords-model predictive control, weighting factor, drives

\section{INTRODUCTION}

The induction motor is one of the most used machines in industrial applications, thanks to its high reliability, low cost and robustness. The strategies that are most used in AC motor drives are Field Oriented Control (FOC) and Direct Torque Control (DTC). In recent years, thanks to the significantly higher microcontroller computational power, it has been possible to implement new control strategies including the Model Predictive Control (MPC).

Until now, the Finite Control Set Model Predictive Control (FCS-MPC) of torque and flux of AC machines has been implemented using a single cost function and using a weighting factor to give importance to the minimization of torque or flux error [1-3]. The calculation of the weighting factor is one of the main problems in this control strategy, and in most cases, it is obtained through iterative processes that are not accepted by many users [4]-[5]-[6].

One of the proposed solutions for predictive torque and flux control for AC machine that does not use weighting factors is the Sequential Model Predictive Control (SMPC) [3], based on a two-stage sequential structure with a single cost function for each stage. For this strategy, the first stage controls the torque and the second stage controls the flux. In the SMPC strategy [3], the first cost function is evaluated for all seven available voltage vectors, then the two voltage vectors that generate the smallest torque error are selected for the evaluation of the flux error.

Finally, between the available two voltage vectors, the voltage vector that minimizes the flux error is selected as global optimal and applied through the inverter.

In this paper, a new control strategy called SMPC-FT is analyzed (FT stands for Flux-Torque). For this strategy, the evaluation of the cost functions is carried out in an inverse way compared to [3]. With SMPC-FT strategy the first cost function is evaluated for all seven voltage vectors available, then the two or more voltage vectors that generate the smallest flux error are selected for the evaluation of the torque error. Among the two (or more) voltage vectors available, a voltage vector that minimizes the torque error is selected.

This means that ideally there are seven SMPC-FT strategies that can be distinguished from the number of vectors used for the second minimization. To identify them, a number from one to seven will be used at the end of the name.

For these strategies, the following figures of merit are analyzed:

- The drive's dynamic response at speed step and load step.

- Response to a simultaneous load and stator flux step.

The first ones have been performed with the aim of obtaining comparative results with what is reported in [3], while the latter to analyses the functioning of the control strategy when an MTPA strategy is used.

In this paper, simulation results are presented to briefly comment on [3] and to give the reader a detailed insight into the workings of this strategy while, at the same time, to 
explain why more than two vectors selected from the first evaluation does not produce desired results.

The other goal of this work is to propose a reverse evaluation sequence in which flux error minimization is given precedence (evaluated first) over torque error which is beneficial when in flux-weakening region of operation.

The paper also explains to the reader why it is still possible to control the machine if, in the reverse sequence, more than two vectors are selected from the first cost function evaluation.

\section{MATHEMATICAL MODEL OF THE INVERTER AND THE INDUCTION MACHINE}

\section{A. Inverter model}

The simulated inverter is a 2-level Voltage Source Inverter (2L-VSI) with ideal switches and with a DC-link of 520V. As regards the inverter circuit and the vectors that can be generated, it is possible to refer to [7].

\section{B. Induction machine}

The dynamic equation of IM in stationary frame $(\alpha, \beta)$ are:

$$
\begin{array}{rl}
\boldsymbol{v}_{\boldsymbol{s}} & =R_{s} \boldsymbol{i}_{\boldsymbol{s}}+d \boldsymbol{\lambda}_{\boldsymbol{s}} / d t \\
\mathbf{0} & =R_{r} \boldsymbol{i}_{\boldsymbol{r}}+d \boldsymbol{\lambda}_{\boldsymbol{r}} / d t-j \omega_{r} \boldsymbol{\lambda}_{\boldsymbol{r}} \\
\boldsymbol{\lambda}_{\boldsymbol{s}} & =L_{s} \boldsymbol{i}_{\boldsymbol{s}}+L_{m} \boldsymbol{i}_{\boldsymbol{r}} \\
\boldsymbol{\lambda}_{\boldsymbol{r}} & =L_{r} \boldsymbol{i}_{\boldsymbol{r}}+L_{m} \boldsymbol{i}_{\boldsymbol{s}} \\
T & =1.5 p\left(\boldsymbol{\lambda}_{\boldsymbol{s}} \wedge \boldsymbol{i}_{\boldsymbol{s}}\right) \\
J_{m} & d \omega / d t=T-T_{L}
\end{array}
$$

where $\boldsymbol{v}, \boldsymbol{i}$ and $\lambda$ are voltage, current and flux vectors with subscript ' $\mathrm{s}$ ' and ' $\mathrm{r}$ ' denoting stator and rotor, respectively. $R_{s}=0.41 \Omega$ and $R_{r}=0.31 \Omega$ are the stator and rotor resistance, respectively. $\omega_{\mathrm{r}}$ and $\omega$ are the electrical and mechanical rotor speed; Ls $=0.09757 \mathrm{H}, \mathrm{Lr}=0.09757 \mathrm{H}$ and $\mathrm{Lm}=0.09187 \mathrm{H}$ are the stator, rotor and mutual inductance, respectively.

$\mathrm{T}$ and $\mathrm{T}_{\mathrm{L}}$ are the motor and load torque; $\mathrm{p}=2$ is the number of pole-pairs and $\mathrm{Jm}=0.062 \mathrm{~kg} . \mathrm{m}^{2}$ is the moment of inertia of the machine.

It is important to note that bold typeface is used for vector quantities and " $\mathrm{j}$ " is a complex operator.

\section{THE CONTROL STRATEGY SMPC-FT}

For the implementation of SMPC-FT, the stator flux $\lambda_{s}$ and stator current $\boldsymbol{i}_{\boldsymbol{s}}$ must be predicted, then from these two quantities it is possible to predict the torque that will be supplied by the machine.

It is important to compensate for the digital delay [8], this means that $\boldsymbol{\lambda}_{\boldsymbol{s}}, \boldsymbol{i}_{\boldsymbol{s}}$ and $T$ must be calculated for the future instant $k+2$. For the implementation of this strategy a flux observer [9] was used; from it for every instant, exploiting the properties of the discrete integral, two information are available, and they are:

- $\lambda_{s}^{k+1}$ which is a predicted stator flux for the future instant $\mathrm{k}+1$, in particular it is the output of the backemf integrator at the present sample $\mathrm{k}$;
- $\lambda_{s}^{k}$ which is the stator flux at the previous instant $\mathrm{k}$, kept in memory.

The first information of the flux observer is used for the prediction of the current and stator flux at the instant $\mathrm{k}+2$, while the second information is just used for the prediction of the stator current at the instant $\mathrm{k}+1$. For prediction of stator current the state equation (7) is used.

$$
\begin{aligned}
& \frac{d i_{s}}{d t}=\frac{1}{\sigma L_{s}}\left(\mathbf{v}_{\mathbf{s}}-\left(R_{s}+R_{r} \frac{L_{s}}{L_{\mathrm{r}}}\right) \mathbf{i}_{\mathbf{s}}+j{ }_{r} \sigma L_{s} \mathbf{i}_{\mathbf{s}}+\frac{\lambda_{s}}{\tau_{r}}-\right. \\
& \begin{array}{ll}
j & \left.{ }_{r} \lambda_{s}\right)
\end{array}
\end{aligned}
$$

where $\sigma=\left(1-L_{m}^{2} /\left(L_{r} L_{s}\right)\right)$ is a leakage factor and $\tau_{r}=L_{r} / R_{r}$ is the rotor time constant. This equation can be obtained starting from (1), using (3) and (4). Using the Euler discretization and based on the measured current, of the voltage vector applied at the instant $\mathrm{k}$ and $\lambda_{s}^{k}$, it is possible to calculate the current at the instant $\mathrm{k}+1$ as below:

$$
\begin{gathered}
\boldsymbol{i}_{\boldsymbol{s}}^{k+1}=\boldsymbol{i}_{\boldsymbol{s}}^{k}+\frac{T_{S}}{\sigma L_{s}}\left(\boldsymbol{v}_{\boldsymbol{s}}^{k}-\left(R_{s}+R_{r} \frac{L_{s}}{L_{r}}\right) \boldsymbol{i}_{\boldsymbol{s}}^{k}+j \omega_{r} \sigma L_{s} \boldsymbol{i}_{\boldsymbol{s}}^{k}\right. \\
\left.+\frac{\lambda_{\boldsymbol{s}}^{k}}{\tau_{r}}-j \omega_{r} \lambda_{\boldsymbol{s}}^{k}\right)
\end{gathered}
$$

In the same way it is possible to obtain $\boldsymbol{i}_{\boldsymbol{s}}^{k+2}$, using the results of equations (8) and the flux observed at the current time $\mathrm{k}$ that is $\lambda_{s}^{k+1}$. The stator flux prediction at the instant $\mathrm{k}+2$ is obtained by the forward Euler discretization of the equation (1), using the stator current $\boldsymbol{i}_{\boldsymbol{s}}^{k+1}$. The equations used are:

$$
\begin{aligned}
& \lambda_{s \alpha}^{k+2}=\lambda_{s \alpha}^{k+1}+T_{S} v_{s \alpha}^{k+1}-R_{s} T_{S} i_{s \alpha}^{k+1} \\
& \lambda_{s \beta}^{k+2}=\lambda_{s \beta}^{k+1}+T_{S} v_{s \beta}^{k+1}-R_{s} T_{S} i_{s \beta}^{k+1}
\end{aligned}
$$

From the prediction of the current and flux at instant $\mathrm{k}+2$, it is possible to calculate the torque, at instant $\mathrm{k}+2\left(T^{k+2}\right)$, using the equation (5). The block diagram for SMPC-FT control strategies is presented in Fig. 1. The two cost functions used for evaluating torque and flux error are (11) and (12).

$$
\begin{aligned}
& g \lambda=\left(\left|\lambda_{s}^{*}\right|-\left|\lambda_{s}^{k+2}\right|\right)^{2} \\
& g T=\left(T^{*}-T^{k+2}\right)^{2}
\end{aligned}
$$

where: $\left|\lambda_{s}^{*}\right|$ is the stator flux reference amplitude, $\left|\lambda_{s}^{k+2}\right|=\sqrt{\left(\lambda_{s \alpha}^{k+2}\right)^{2}+\left(\lambda_{s \beta}^{k+2}\right)^{2}}$ is the predicted stator flux modulus at the instant $\mathrm{k}+2, T^{*}$ is the reference torque exiting from the speed PI regulator.

The control starts from the evaluation of $g_{\lambda}$, it is evaluated for all the seven voltage vectors that can be supplied by the inverter, then two or more voltage vectors that generate the smallest error are chosen for the evaluation of $g_{T}$, and finally the voltage vector selected is that, among the previous ones, which minimizes $g_{T}$.

It is important to note that the number of voltage vectors selected for the evaluation of the torque cost function depends on the type of SMPC-FT strategy used. 


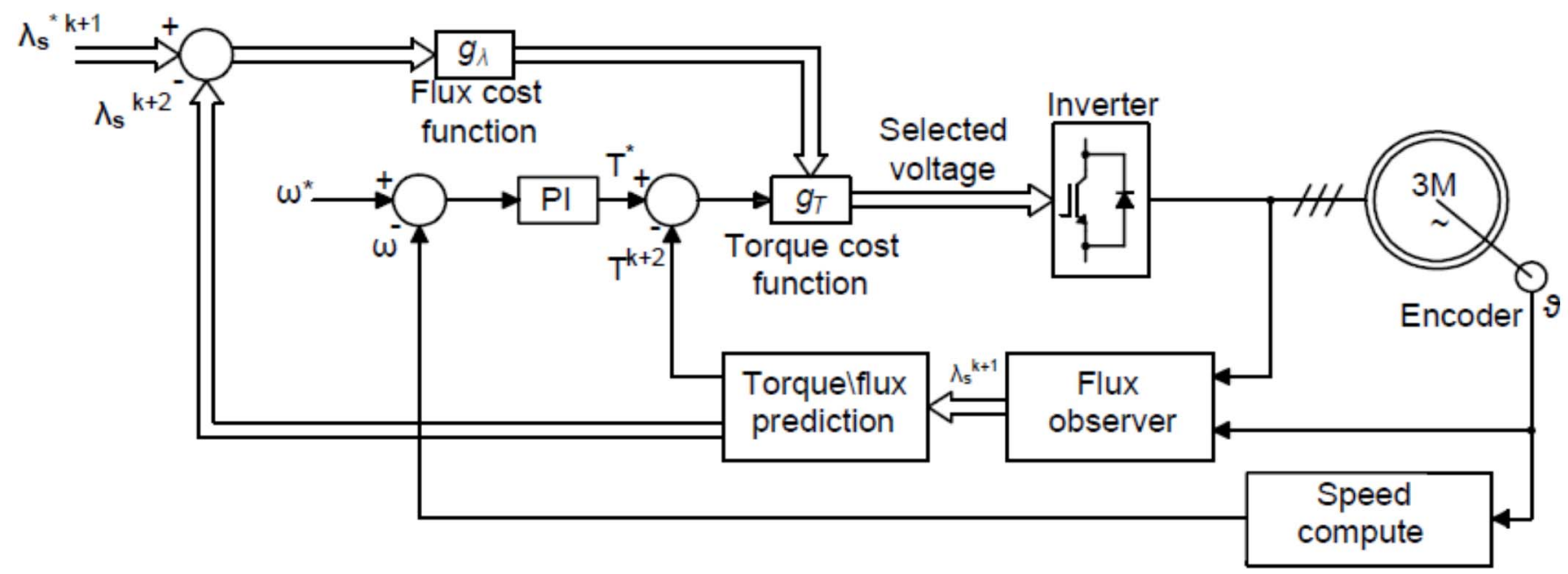

Fig. 1. The block diagram for SMPC-FT control strategies.

TABLE I. ANALYSED SMPC-FT STRATEGIES.

\begin{tabular}{|c|c|c|}
\hline Strategy & $\begin{array}{c}\text { Number of voltage } \\
\text { vector used for } \\
\text { evaluation of } \boldsymbol{g}_{\boldsymbol{\lambda}}\end{array}$ & $\begin{array}{c}\text { Number of voltage } \\
\text { vector used for } \\
\text { evaluation } \boldsymbol{g}_{\boldsymbol{T}}\end{array}$ \\
\hline$S M P C-F T 2$ & 7 & 2 \\
\hline$S M P C-F T 3$ & 7 & 3 \\
\hline$S M P C-F T 4$ & 7 & 4 \\
\hline$S M P C-F T 5$ & 7 & 5 \\
\hline$S M P C-F T 6$ & 7 & 6 \\
\hline
\end{tabular}

TABLE II. PRINCIPALS CONTROL PARAMETERS.

\begin{tabular}{|l|c|}
\hline Sample Time & $4 \cdot 10^{-5}(\mathrm{~s})$ \\
\hline DC link voltage: $\mathrm{V}_{\mathrm{DC}}$ & $520(\mathrm{~V})$ \\
\hline Bandwidth speed regulator:? ${ }_{b}$ & $314.16(\mathrm{rad} / \mathrm{s})$ \\
\hline $\begin{array}{l}\text { Proportional gain of the speed } \\
\text { regulator }\end{array}$ & $\omega_{b} \cdot J_{m}$ \\
\hline Integral gain of the speed regulator & $\omega_{b}^{2 \cdot} J_{m}$ \\
\hline
\end{tabular}

Table I shows all the possible SMPC-FT strategies that have been analyzed, however, the strategy SMPC-FT7 has not been analyzed

because with this strategy only the torque error would be minimized, neglecting the minimization of the flux error.

For the same reason the SMPC-FT1 was not analyzed, in this case the torque error is not minimized. All the strategies have been simulated.

\section{RESULTS}

Table II shows the principal control parameters. For all the SMPC-FT strategies, shown in Table I, the response to a speed step and a load step was tested. In all the following figures, at 0.2 seconds a step speed reference $\left(\omega^{*}\right)$ was imposed equal to $100 \mathrm{rad} / \mathrm{s}$, while at $0.6 \mathrm{~s}$ a load step of $40 \mathrm{Nm}$ was applied.
TABLE III. PRINCIPALS SETUP PARAMETERS.

\begin{tabular}{|c|c|c|c|c|}
\hline \multicolumn{2}{|c|}{ Nameplate data } & \multicolumn{3}{|c|}{ Equivalent Circuit Parameters } \\
\hline Quantity & Value & Quantity & Symbol & Value \\
\hline $\begin{array}{l}\text { Rated } \\
\text { power }\end{array}$ & $7.5 \mathrm{~kW}$ & $\begin{array}{c}\text { Stator } \\
\text { resistance }\end{array}$ & $R_{s}$ & $0.41 \Omega$ \\
\hline $\begin{array}{l}\text { Rated } \\
\text { current }\end{array}$ & $17 \mathrm{~A}$ & $\begin{array}{l}\text { Rotor } \\
\text { resistance }\end{array}$ & $R_{r}$ & $0.31 \Omega$ \\
\hline $\begin{array}{c}\text { Rated } \\
\text { voltage }\end{array}$ & $380 \mathrm{~V}$ & $\begin{array}{c}\text { Leakage } \\
\text { inductances }\end{array}$ & $L_{l r}, L_{l s}$ & $5.7 \mathrm{mH}$ \\
\hline $\begin{array}{l}\text { Nominal } \\
\text { frequency }\end{array}$ & $50 \mathrm{~Hz}$ & $\begin{array}{c}\text { Magnetizing } \\
\text { inductance }\end{array}$ & $L_{m \text {-unsat }}$ & $91.0 \mathrm{mH}$ \\
\hline $\begin{array}{l}\text { Rated } \\
\text { speed }\end{array}$ & $1460 \mathrm{rpm}$ & pole-pairs & $p$ & 2 \\
\hline
\end{tabular}

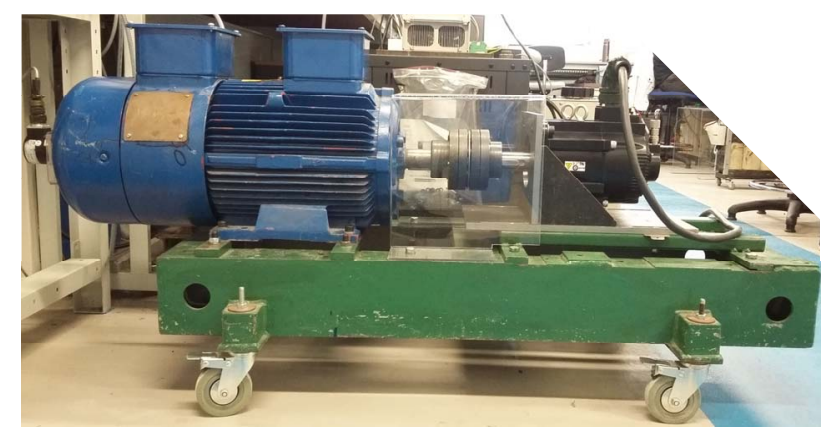

Fig. 2. Setup used.

From $0 \mathrm{~s}$ to $0.2 \mathrm{~s}$ the machine is fluxing at $\left(\left|\lambda_{\mathrm{s}}^{*}\right|=0.8 \mathrm{Vs}\right)$ because otherwise the induction machine is not able to give a torque, and the torque reference is forced to zero during fluxing period. The SMPC-FT2 and SMPC-FT3 strategies are analyzed in detail below.

Table III shows the principals setup parameters and Fig. 2 shows the setup used in this work. 


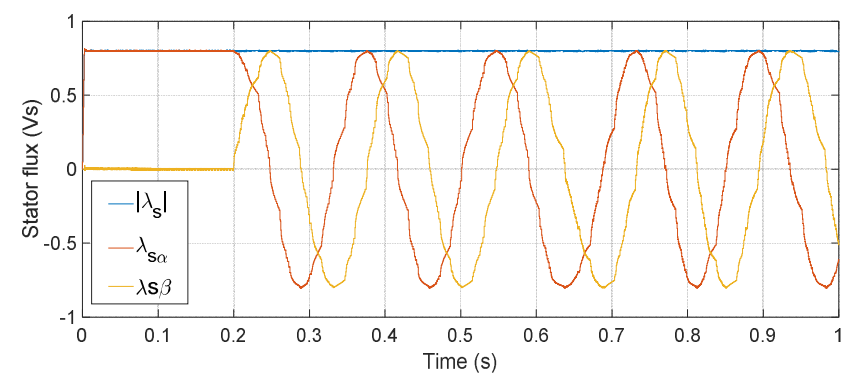

Fig. 3. Stator flux in the stationary frame $(\alpha, \beta)$.

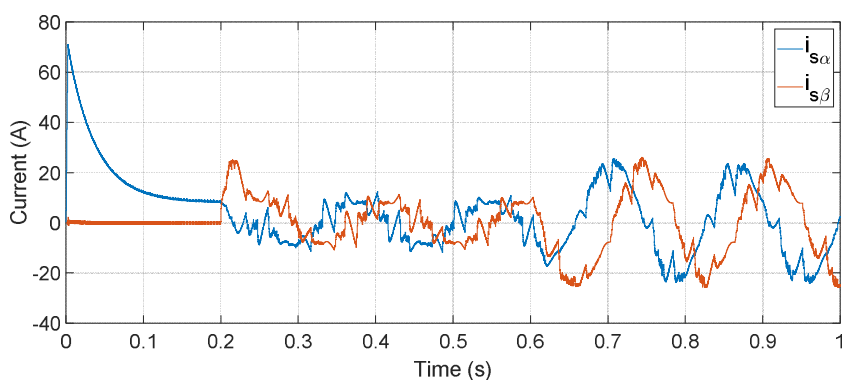

Fig. 4. Stator current in the stationary frame $(\alpha, \beta)$.

\section{A. Analysis and results obtained from the SMPC-FT2 strategy}

With the SMPC-FT2 strategy at each control step to evaluate $g \lambda, \lambda_{s \alpha}^{k+2}$ and $\lambda_{s \beta}^{k+2}$ are calculated, for all the seven voltage vectors available. In particular, at the first control step, all the vectors different from zero allow to obtain the same flux error, i.e. all give the same flux amplitude, while the vector $v_{0}$ is excluded because it is not able to flux the machine consequently generates a $g_{\lambda}$ greater than all the others.

Therefore, from the first minimization the two selected vectors are $v_{1}$ and $v_{2}$, but only because the evaluation of $g_{\lambda}$ is made in sequential way starting from the voltage vector with lower index. $v_{1}$ and $v_{2}$ are then used for the evaluation of the torque error but at the first control step the current is zero and therefore both vectors return $T^{k+2}=0$ and therefore also $g_{T}=0$.

In conclusion to the first control step the vector $v_{1}$ is applied to the machine and in this case the selection of $v_{1}$ instead of $v_{2}$ depends only on the implementation.

Fig. 3 and Fig. 4 show how the application of $v_{1}$ causes the increment of flux and current in the $\alpha$-axis.

From the second control step it is possible to demonstrate, using equations (9) and (10) for calculating the flux amplitude, that $v_{1}$ is the vector that reduces the flux error more quickly, while $v_{2}$ and $v_{6}$ are the two possible second choices.

In other words, $v_{2}$ and $v_{6}$ give the same increment of flux amplitude $\left|\Delta \lambda_{s}^{k+2}\right|_{6,2}$ but less than the increment $\left|\Delta \lambda_{s}^{k+2}\right|_{1}$ generated by $v_{1}$.

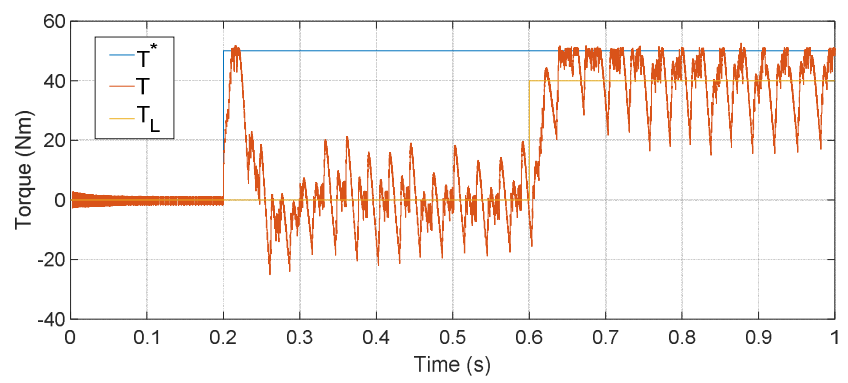

Fig. 5. Torque delivered by the machine, reference torque and required load torque.

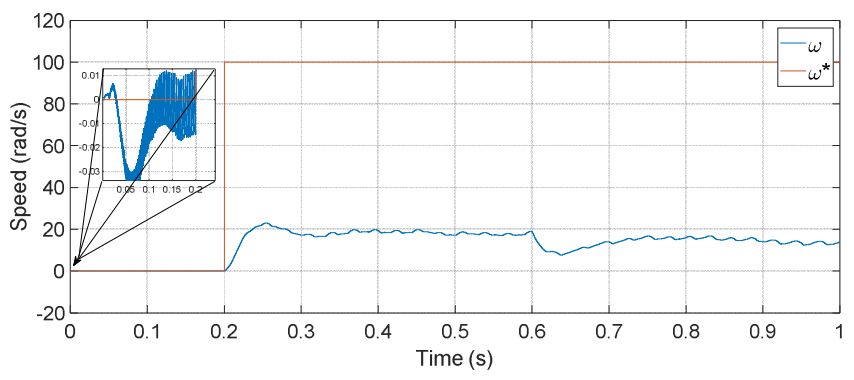

Fig. 6. Reference and measured machine speed.

As long as the flux error between reference flux $\left(\left|\lambda_{s}^{*}\right|\right)$ and predicted flux $\left(\left|\lambda_{s}^{k+2}\right|\right)$ is less than $\left|\Delta \lambda_{s}^{k+2}\right|_{1}$, the two vectors selected by the minimization of $g_{\lambda}$ are always $v_{1}$ and $v_{2}$; they are also used for the minimization of the torque error, but $v_{2}$ is always excluded because it would cause $T^{k+2} \neq 0$ and therefore a greater $g_{T}$.

As soon as the flux error between $\left(\left|\lambda_{s}^{*}\right|\right)$ and $\left(\left|\lambda_{s}^{k+2}\right|\right)$ becomes lower than $\left|\Delta \lambda_{s}^{k+2}\right|_{1}$ the two vectors selected by the flux error minimization are $v_{2}$ and $v_{6}$, in fact they allow to have a lower flux error.

The problem is that both these vectors if applied to the machine cause $T \neq 0$. In other words, they are not able to respect the torque reference during the fluxing phase.

Consequently, as it is possible to observe from the Fig. 5 and Fig. 6, during the fluxing phase of the machine, torque and therefore speed noise are present.

The same analyses can be made from $0.2 \mathrm{~s}$ onwards when the torque reference is different from zero, and it is possible to conclude that using for the minimization of the torque error only the two vectors that generate the smallest flux error does not allow to deliver the desired torque, in fact the vectors strictly necessary for the minimization of flux error are selected.

For example, after $0.2 \mathrm{~s}$ when $T^{*} \neq 0$, as soon as the flux exceeds the reference to allow the reduction of $g_{\lambda} v_{0}$ and a non-zero vector are selected

This non-zero vector selected generates a component of flux in phase opposition and it is systematically excluded by the torque minimization, because it would increase $g_{T}$, so the selected vector is $v_{0}$ for more than one control step not allowing torque delivery, as is possible to observe from the Fig. 4. 


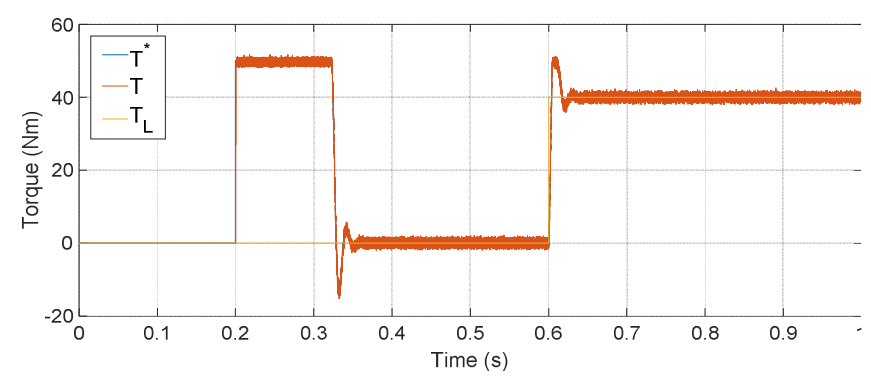

Fig. 7. Torque delivered by the machine, reference torque and required load torque.

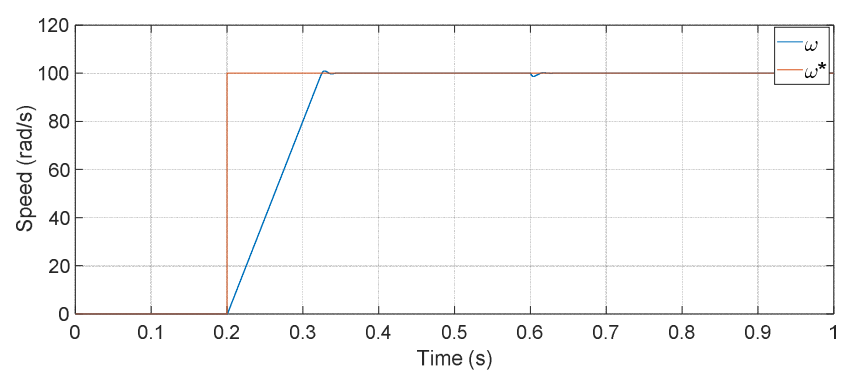

Fig. 8. Real speed and reference speed of the machine.

\section{B. Analysis and results obtained from the SMPC-FT3 strategy}

As for the SMPC-FT2 strategy at each control step to evaluate $g_{\lambda}, \lambda_{s \alpha}^{k+2}$ and $\lambda_{s \beta}^{k+2}$ are calculated, for all the seven voltage vectors available, knowing $\lambda_{s \alpha}^{k+2}$ and $\lambda_{s \beta}^{k+2}$ it is possible to calculate the stator flux module.

From the first minimization, as before, the selected vectors are $v_{1}, v_{2}$ and $v_{3}$, because also in this case the evaluation of $g_{\lambda}$ is made in sequential way starting from the voltage vector with lower index.

These three vectors are used for the evaluation of $g_{T}$ and at the end $v_{1}$ is applied to the machine. When the flux error between $\left(\left|\lambda_{s}^{*}\right|\right)$ and $\left(\left|\lambda_{s}^{k+2}\right|\right)$ is more than $\left|\Delta \lambda_{s}^{k+2}\right|_{1}$, the three voltage vectors that generate the smallest flux error are $v_{2}, v_{6}$ and $v_{0}$, with the first two vectors that are the same selected with the SMPC-FT2 control strategy.

Thanks to the possibility to choose also $v_{0}$, for the minimization of $g_{T}$, all the problems during the fluxing of the machine are avoided, this means that there is no torque and speed noise and indeed $i_{s \beta}=0$ as can be seen from the Fig. 7, Fig. 8 and Fig. 9.

So, whenever the flux error is less than $\left|\Delta \lambda_{s}^{k+2}\right|_{1}$, the vector $v_{0}$ is applied, causing a flux reduction.

Consequently the flux error between $\left(\left|\lambda_{s}^{*}\right|\right)$ and $\left(\left|\lambda_{s}^{k+2}\right|\right)$ becomes higher than $\left|\Delta \lambda_{s}^{k+2}\right|_{1}$, allowing the application of $v_{1}$ in the subsequent control steps and avoiding all the problems of torque noise.

With this logic the machine is fluxed up to $0.2 \mathrm{~s}$. From $0.2 \mathrm{~s}$ onwards when $T^{*} \neq 0$, if the flux exceeds the reference in addition to the $v_{0}$ and to the non-zero voltage vector that generates a component of flux in phase opposition, (which

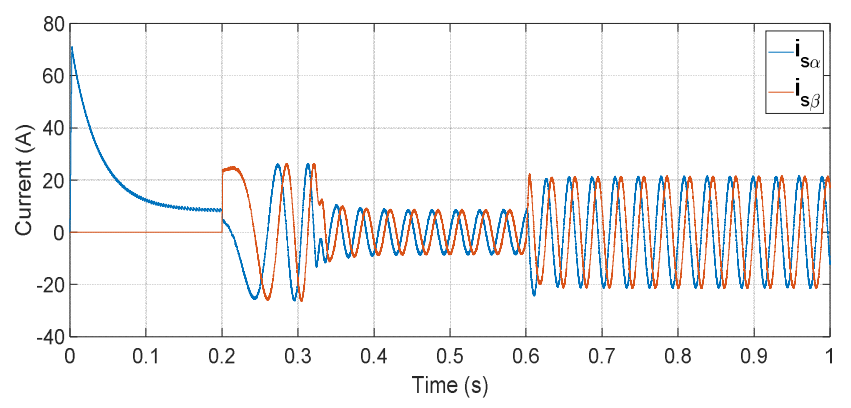

Fig. 9. Stator current in a fixed frame $(\alpha, \beta)$.

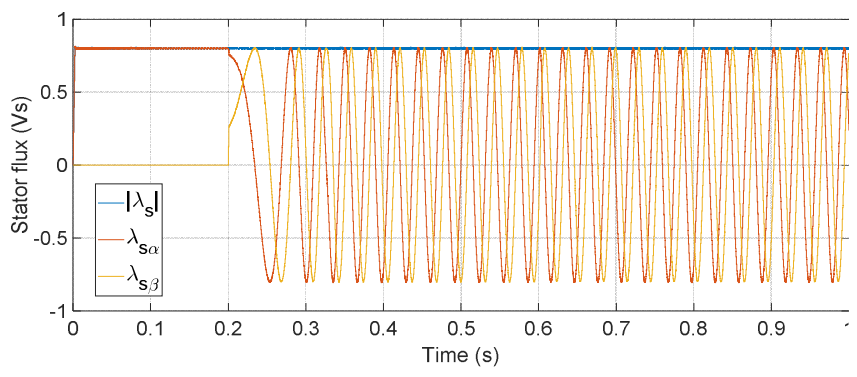

Fig. 10. Stator flux in a fixed frame $(\alpha, \beta)$.

were the vectors chosen by the minimization of $g_{\lambda}$ with the SMPC-FT2 strategy).

With SMPC-FT3 there is the possibility to choose intermediate voltage vector that allows to deliver torque but at the same time able to support the stator flux even if with a greater error as can be seen from Fig. 10.

Therefore, it is possible to conclude that the increase of vectors available for the evaluation of torque error allows this control strategy to work in the correct way.

\section{Comparison with the results obtained using the strategy proposed in [3]}

In Fig. 11 and Fig. 12 are shown the results in terms of torque and stator flux obtained using the strategy [3], when:

- between $0 \mathrm{~s}$ and $0.2 \mathrm{~s}$ the machine is fluxed to $0.8 \mathrm{Vs}$.,

- at $0.2 \mathrm{~s}$ a speed step equal to $100 \mathrm{rad} / \mathrm{s}$ is imposed,

- and at $0.6 \mathrm{~s}$ a load step equal to $40 \mathrm{Nm}$ is required.

The sequence of commands listed is exactly the one used in the SMPC-FT2 and SMPC-FT3 strategies.

Comparing the results shown below with those obtained with the SMPC-FT3 strategy, it is possible to state that the two strategies are equivalent. However, selecting more than two vectors for SMPC-TF [3] produces torque and flux distortions and the underlying phenomenon. 


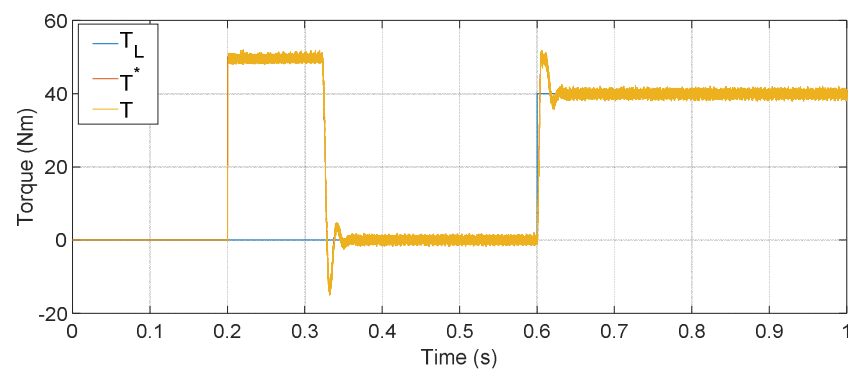

Fig. 11. Torque delivered by the machine, reference torque and required load torque.

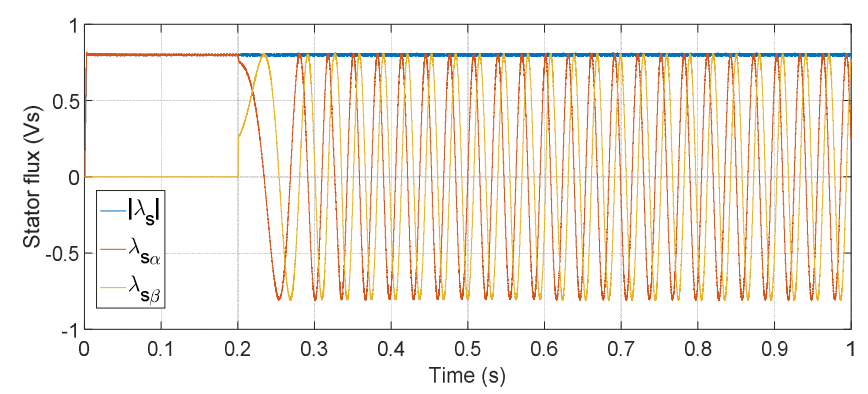

Fig. 12. Stator flux in a fixed frame $(\alpha, \beta)$.

\section{CONCLUSIONS}

This paper analyses a new control technique applied to an induction motor based on the Model Predictive Control, which can be used in high-performance electric drives. The control technique is called SMPC-FT and represents a group of possible strategies.

This group of strategies performs a sequential evaluation of the cost functions associated with the torque and flux errors. By using these strategies, it is possible to avoid all the problems present in the defining the weights typical for a single cost function MPC.

The results for some possible SMPC strategies with normal sequence optimization and reverse sequence optimization was reported.

\section{ACKNOWLEDGMENT}

The authors Cristian Garcia, Margarita Norambuena and Jose Rodriguez acknowledge the support of Conicyt through Fondecyt Initiation Research Projects 11180235 and 11180233, Fondecyt Research Project 1170167 and project AC3E Basal-FB0008.

\section{REFERENCES}

[1] S. A. Davari, D. A. Khaburi, P. Stolze, and R. Kennel, "An improved Finite Control Set- Model Predictive Control (FCS-MPC) algorithm with imposed optimized weighting factor," in Proc. 14th European Conf. Power Electronics and Applications, Aug. 2011, pp. 1-10.

[2] M. Norambuena, C. Garcia, and J. Rodriguez, "The challenges of predictive control to reach acceptance in the power electronics industry," in Proc. 7th Power Electronics and Drive Systems Technologies Conf. (PEDSTC), Feb. 2016, pp. 636-640.

[3] M. Norambuena, J. Rodriguez, Z. Zhang, F. Wang, C. Garcia, R. Kennel, "A Very Simple Strategy for High Quality Performance of AC Machines Using Model Predictive Control", IEEE Transactions on Power Electronics, vol. 34, no. 1, pp. 794-800, 2019.

[4] Z. Zhang, W. Tian, W. Xiong, and R. Kennel, "Predictive torque control of induction machines fed by 3L-NPC converters with online weighting factor adjustment using Fuzzy Logic," in Proc. IEEE Transportation Electrification Conf. and Expo (ITEC), Jun. 2017, pp. 84-89.

[5] P. Cortes, S. Kouro, B. La Rocca, R. Vargas, J. Rodriguez, J. I. Leon, S. Vazquez, and L. G. Franquelo, "Guidelines for weighting factors design in model predictive control of power converters and drives," in Proc. IEEE International Conference on Industrial Technology ICIT 2009, 10-13 Feb. 2009, pp. 1-7.

[6] C. A. Rojas, J. Rodriguez, F. Villarroel, J. R. Espinoza, C. Silva, and M. Trincado, "Predictive torque and flux control without weighting factors," IEEE Transactions on Industrial Electronics, vol. 60, no. 2, pp. 681-690, 2013.

[7] C. F. Garcia, C. A. Silva, J. R. Rodriguez, P. Zanchetta, and S. A. Odhano, "Modulated Model Predictive Control with Optimized Overmodulation," IEEE J. Emerg. Sel. Top. Power Electron., pp. 1-1, 2018.

[8] P. Cortes, J. Rodriguez, C. Silva, and A. Flores, "Delay Compensation in Model Predictive Current Control of a Three-Phase Inverter," IEEE Trans. Ind. Electron., vol. 59, no. 2, pp. 1323-1325, Feb. 2012.

[9] S. A. Odhano, A. Boglietti, R. Bojoi, and E. Armando, "Unified directflux vector control of induction motor self-commissioning drive with analysis of parameter detuning effects," in IEEE Energy Conversion Congress and Exposition (ECCE-2013), 2013, pp. 2071-2078 